of a large number in a single film. We incline to the view that there is a distinct tendency for positive findings to occur in the urine passed 24 hours after the summit of the pyrexial " spike." We also found that spirochætes may be present in striking abundance on the fourteenth to sixteenth day. Four of our cases which had been negative for several preceding days showed this. In this connexion it is interesting to recall the similar behaviour of the spirochæte of hæmorrhagic jaundice.

Preparation of films. - The method we have adopted in preparing the films is as follows :-

Ten cubic centimetres of the urine are centrifuged at high speed for 15 minutes. The supernatant fluid is then pipetted off very gently, leaving the deposit and a layer of urine about $3 \mathrm{~mm}$. in depth over this. Five cubic centimetres of distilled water are then added, and the precipitate thoroughly washed. The fluid is again centrifuged for a quarter of an hour, and the supernatant fluid is again pipetted off very carefully. The deposit is then thoroughly stirred with a platinum loop, and a film is made by superimposing three loopfuls on a clean microscopic slide. The piled-up drop thus obtained is dried in the incubator. The resulting film is circular, with a diameter of about $4 \mathrm{~mm}$. and represents the sediment of about 1 c.c. of the original urine.

In the earlier stages of our work we used thicker films, made by adding further loopfuls of urine sediment to the dried film and again evaporating, but we now consider that single-layer films give the better results. Fearing at one time, after several consecutive negative films, that we might lose some spirochætes during the process of staining and washing through lack of fixative, we added a trace of eggalbumen, but the results obtained were no better than by the ordinary method.

It is our custom to make four films, each from a different urine sediment, on one slide. This ensures equality of staining, and each film acts as a control to the others, which is important in view of the erratic staining properties of spirochrtes by the silver method. We have never yet found all these four films on one slide to be positive at the same time-a sufficient guarantee that the spirochrete did not originate in any of our reagents.

Staining methods. -We have stained the majority of our specimens by a modified Fontana silver method as follows :-

The film is washed gently for two minutes with a solution of 8 per cent. formalin and 1 per cent. glacial acetic acid in distilled water. This fixes the film to some extent and dissolves out some of the remaining urine salts. The film is then washed in absolute alcohol for one minute and allowed almost to dry. When nearly dry it is washed again for a few seconds with distilled water and then flooded with a hot 5 per cent. tannic acid solution containing 1 per cent. of carbolic acid. This mordant is poured on steaming from a test-tube, and is allowed to act for two minutes. The film is then thoroughly washed in distilled water. The silver solution used is 2 per cent. silver nitrate in distilled water, to which the faintest trace of ammonium hydrate-just enough to give a slight opalescence--is added immediately before use. This is used cold, and is pipetted over the film in a slow and continuous stream until the necessary depth of staining - a dark-brown colour - is obtained. The slide is then washed well in distilled water, and dried with a current of cold air by means of a "puffer" or a Politzer bag. In our opinion the use of blotting-paper in drying any delicate film is unjustifiable. The film should be mounted in Canada balsam; for if cedar-wood oil is placed directly upon the film the spirochætes are decolourised in a day or two. Spirochætes stained by this method and examined with a $1 / 12$ objective and 6 ocular appear jet-black against a faint grey or brown background. When examined by dark-ground illumination they are brilliantly white and clear against the surrounding black. With Giemsa's stain the spirochrotes stain pale red with a tinge of blue as seen with ordinary illumination, and are of a golden colour when viewed with a dark-ground illumination.

An alternative staining method to the Giemsa or the modified Fontana is with carbol-fuchsin. The film is mordanted as above, and is then stained for an hour in the incubator in strong carbol-fuchsin (Ziehl-Neelsen). It is then washed in distilled water. The spirochretes stain pink by this method. We have employed it only occasionally on account of the considerable ocular strain caused by prolonged searching. A spirochæte stained black, or appearing golden against a dark background, is more easy to see than one stained faintly red.
Presenoe in the urine.--Their number in the urine is variable. From the same specimen of the urine four films of the size of $5 \mathrm{~mm}$. were searched, each for half an hour, and only one spirochrte was discovered. On another occasion, from the same patient, 22 spirochætes were found in one film. Before a urine was called negative at least three, and often four, films were made and searched, each for half an hour.

Morphology.-These spirochætes are actively motile. Their average length by ocular measurement is $8 \cdot 15 \mu$ and they show an average of five curves. The largest one (possibly two joined together) was $12.5 \mu$ with 10 curves. The shortest was $5 \mu$ with $2 \frac{1}{2}$ spirals. By micro-photographic measurement the average length was $78 \mu$ with an average of 5.2 curves. The thickness is about $0.3 \mu$. The spirals vary in depth, which is a common feature also in $T$. pallidum.

Associated with the typical spirochæte were straight bodies, having the same measurement and the same staining properties and similar in appearance except that they possessed no distinct spirals. We have not included these in our positive findings, but as all intermediate stages were found between the typical treponema with its sharp spirals to the straight body, it is possible that the latter is a variation of the former. We have seen similar atypical forms in dried films of $T$. pallidum. Some of the typical forms show nodes or thickenings, as is also seen in T' pallidum. The spirochæte is thicker in the centre and tapers towards the ends, and some seem to show a faint flagellum at one or both ends. This spirochæte resembles the T. pallidum in many respects, but differs from it in that the average length is less and the spirals are fewer. It is about half the length of the Spirochoeta reourrenti (Obermeieri).

We have not yet succeeded in finding this spirochæte in blood films or in cultivating it from the blood stream as Reimer claims to have done, nor have we, up to the present, done any work regarding its pathogenicity to man and animals.

We have to thank Captain A. R. Friel, S.A.M.C., for allowing us to use his electric centrifuge. We wish also to express our indebtedness to Captain E. W. Ferguson, A.A.M.C., who has been good enough to search some films for us and to check our findings, and to Private J. M. Stanley, who has done much of the routine work entailed by our investigations. Our thanks are especially due to Dr. A. C. Coles, who has measured 80 of these spirochrtes for us and has prepared the admirable photo-micrographs which illustrate so clearly the subject of this paper.

The whole communication is clearly in the nature of a preliminary note.

\section{OPERATION FOR THE REPAIR OF THE CRUCIAL LIGAMENTS.}

BY ERNEST W. HEY GROVES, M.S. LOND., F.R.C.S. ENG., MAJOR, R.A.M.C. (T.F.)

IT is a matter of common knowledge that cases of rupture of the crucial ligaments are now much more frequently recognised than formerly. This is due to routine $X$ ray examination, which often reveals the fracture of one or other of the tubercles of the tibial spine, and also to the greater frequency of "exploratory" operations upon disabled knee-joints. It is also a general experience that this injury is an extremely serious one, which produces permanent total disablement for active pursuits and which necessitates a very prolonged treatment by immobilising apparatus.

But whilst the frequency and importance of this injury is becoming more widely known there has not been any corresponding advance in methods of treatment. A rigid plaster or leather case to be worn for a year, followed by a hinged apparatus, represents the generally accepted method. It is impossible to regard intra-articular suture of the ligaments, either by soft sutures or by wire, as an efficient procedure or as one free from the risk of leaving loose bodies in the joint.

Some years ago I worked out a method of replacing the crucial ligaments by tendons or fascial bands, in the dissecting room, but it has only been recently that an opportunity has arisen for putting it to a practical test. It has, however, been so easy of performance and so 
FIG. 1.

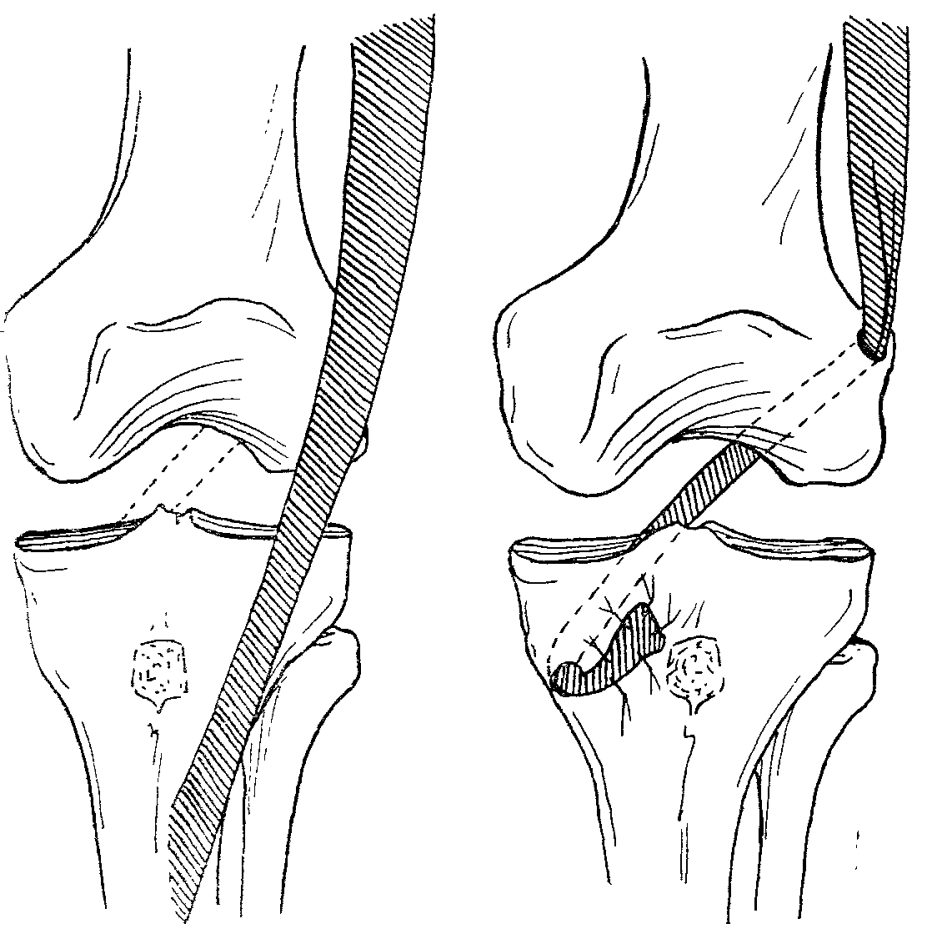

Formation of a new anterior crucial ligament from the ilio-tibial band of fascia.

satisfactory in results that $I$ think it worth while to publish this preliminary note, in the hope that the new suggestion may prove of value to others.

\section{Principle of the Operation.}

The principle of the operation consists in forming a new anterior crucial ligament from the ilio-tibial band and a new posterior ligament from the tendon of the semi-ten. dinosus. In each case the new ligament retains its upper attachment in the thigh and is threaded through new canals bored in the femur and tibia, and is sewn to the outer surface of the latter bone.

Exposure of the joint.-A wide horseshoe incision is made across the joint, the lowest point being below the tibial tubercle and the lateral ends running up to the lines of the hamstrings on each side. The tubercle of the tibia is freed by two saw cuts, one behind and parallel to the ligamentum patella and the other at right angles to the tibia below the tabercle. The patella is turned upwards sufficiently to expose the interior of the joint. In this act it is important to avoid cutting the ilio-tibial band. The joint ilio-tibial band. The joint condition of the crucial ligaments and of the spine of the tibia is ascertained.

Formation of " new anterior crucial ligament.--The lower end of the fascia lata is exposedand defined upwards above the level of the external condyle of the femur and downwards for about an inch below the tubercle of the tibia. At the latter point it is cut across and dissected upwards free from the underlring structures. With the knee fully flexed, the two points of attachment of the torn ligament are clearly defined and cleared of soft tissue. With a $\frac{1}{3}$-inch twist drill a canal is bored from within the joint upwards and outwards through the external condyle of the femur and another lownwards and inwards through the internal tuberosity of the tibia, beginning in each case with
FI: 2.

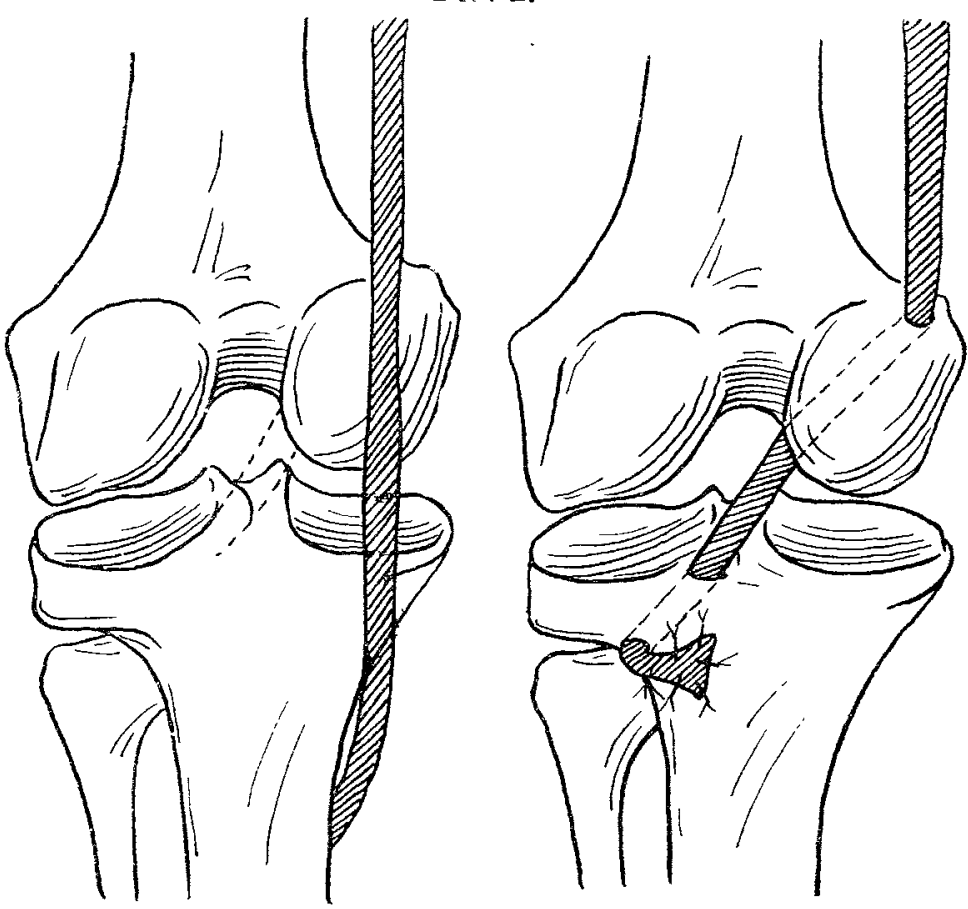

Formation of a new posterior crucial ligament from the tendon of the semi-tendinosus.

the point of attachment of the original ligament. A probe is tied to the free end of the ilio-tibial band and by its means this piece of fascia rolled. up as a cord is threaded through the femur and the tibia and drawn tight. When it emerges below the knee the fascial ligament is turned upwards and sewn to the deep fascia and periosteum of the tibia. (Fig. 1.)

Formation of a new posterior crucial ligament.--If both ligaments have to be re-formed the posterior will naturally be repaired first. The inner limb of the horseshoe incision is prolonged backwards and upwards until the inner hamstring is exposed and the tendon of the semi-tendinosus is defined. This is cut from its lower attachment $1 \frac{1}{2}$ inches below the joint. New canals are then formed by drilling from within the joint upwards, inwards, and backwards through the internal condyle of the femur, and then downwards and
HIG. 3.

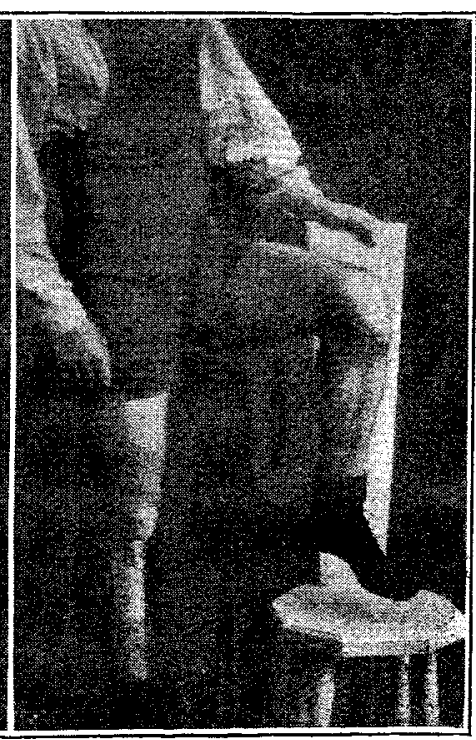
outwards through the external tuberosity of the tibia. Through these canals the semi-tendinosus tendon is threaded and fixed to the periosteum of the tibia. (Fig. 2.)

Closure of the joint.-The tubercle of the tibia is refixed in its original position by an ivory or metal nail and the joint capsule carefully closed by catgut sutures.

After-treatment.-The knee is kept on a back splint for about a fortnight, and then when the skin incision is soundly healed it is removed daily from the splint for gentle massage and passive movements.

After one month the splint is discarded and the patient is allowed up on crutches, and then full use of the limb is gradually restored, as this can be done naturally without pain or force.

The above operation was performed on April 25th, 1917, for A. D., whose knee had been injured by a kick from a horse. His knee was unstable and weak, so that he could neither stand nor walk without the support of a knee-splint.

The recent photographs (Fig. 3) show the patient standing upon the injured left leg and also bending the same. He can walk freely without a limp and has now returned to work. 


\section{A REPORT ON \\ THE TREATMENT OF A SERIES OF RECENTLY INFLICTED WAR WOUNDS WITH "PROFLAVINE."}

$\mathrm{BY}$

\author{
CAPT. L. COLLEDGE, CAPT. HAMILTON DRUMMOND \\ LIEUT. R. T. WORTHINGTON, \\ SURGICAL OFFIGKRS, - CASUALTY CJEARING STATION \\ AND \\ Major J. W. MCNEE, CAPT. A. F. SLADDEN \\ CAPT. J. E. MCCARTNEY, \\ - MOBILE LABORATORY.
}

THIS report on the action of proflavine in the treatment of recently inflicted wounds is to be read in connexion with a communication by Captain Hamilton Drummond and Captain J. W. MoNee in THE LANCET of Oct. $27 \mathrm{th}$, on the results obtained with acriflavine (flavine).

The sample of proflavine used in the present instance was put at our disposal by Surgeon-General Sir Anthony Bowlby early in August, and the tests have been made so that ready comparison of the effects of the two salts has been possible.

Proflavine (diamino-acridine-sulphate) is, as Browning and his colleagues have explained, a preliminary product in the manufacture of acriflavine or flavine (diamino-methylacridinium-chloride), and is therefore both easier and cheaper to make.

The cases described in this report have been under the care of the surgical officers of a Casualty Clearing Station (Captain Colledge, Captain Drummond, and Lieutenant Worthington), and the bacteriological work has been carried out in a mobile laboratory.

Soupe of the tests. - The tests, for purposes of comparison, have followed the same lines as those detailed for acriflavine. A solution of 1 in 1000 in normal saline has generally been employed as a primary application, followed later by the use of a more dilute solution of 1 in 5000 .

Number of cases, do.-In all 43 cases have been treated with proflavine : in a number of instances, however, multiple injuries were present, so that nearly 60 wounds are included in the series. It has happened that the series of cases has included a large percentage of very serious injuries, so that the test of the antiseptic has been a severe one.

Classification of cases. - It seems unnecessary to classify the wounds in detail, but it may be stated that the cases include 7 in which large juints were involved (knee 3 times, shoulder twice, and elbow twice), 10 severe compound fractures of limbs, and 4 where large blood-vessels were injured.

A few illustrative cases may be given in detail.

A. Wounds of joints.-CASE 1.-Wound of the shoulder-joint with fracture of the great tuberosity of the humerus and very extensive muscle damage, necessitating removal of most of the deltoid muscle. The wound, after treatment with proflavine, was closed except for two small drainage-t ubes. These were soon removed, and passive movements of the joint were begun on the twelfth day.

CASE 2.-Wound of the knee-joint. The foreign body was impacted in the spine of the tibia, and lying so far back between the condyles of the femur that complete exposure of the joint cavity by eutting through the ligamentum patellæ was necessary. The joint was sewn second day about 10 co of sterile blood-stained fluid was aspirated from second day about 10 c.c. of sterile blood-stained fluid was aspirated from the joint. The wound healed perfectly and
begun on the thirteenth day after the injury.

CASE 3.-A shell wound causing a compound fracture of the humerus, and ofening up the shoulder-joint. The joint was oxtensively damaged, and the surrounding muscles were much lacerated. The wound was cleaned up as far as possible, but this proved very difficult. Large fragments of the upper third of the humerus were perforce removed, leaving a complete gap. The wound, which could not be closed, was treated with 1 in 1000 proflavine for the first four quickly, and has never suppurated.

CASE 4.-A wound over the right patella, comminuting the bone and opening the knee-joint. A flap was turned up so as to expose the whole joint in front, and the foreign body and the shattered patella were both removed. The joint was irrigated with 1 in 5000 proflavine, wound were completely closed. Healing by first intention occurred.

B. Compound fractures.-CASE 1.-An aviator, shot while flying. A machine-gun bullet fractured the left tibia and fibula, causing also great estruction of the muscles of the calf. The posterior tibial artery wa torn across, and ligatures were put round both artery and vein. The untouched for 36 hours. No inflammation occurred, and the patien was able to be evacuated to the base on the tenth day.

dracture of a leg which one of us (H. D.) has seen recover without amputation. The notorious frequency of gas gangrene in cases of this kind, where the posterior tibial vessel has been destoyed, must also be remarked upon.

Case 2.-A severe compound fracture of the femur. The site of fracture was exposed by joining the entrance and exit wounds. cutting through the vastus externus completely in the middle third of
the thigh. Several large detached fragments of bone were removed. the thigh. Several large detached fragments of bone were removed. The cavity was washed out with 1 in 1000 profiavine, the muscl sutured with catgut. and the wound was then closed except for on Carrel tube inserted from the site of the entry wound. The Carre tube was removed on the fourth day, no suppuration whaterer having
occurred. This patient was evacusted to the base on the sixth day after injury.

CASE 3.-A gunshot wound of the forearm. causing compound racture of the ulna and very considerable laceration of the surround ng muscles. The entrance and exit wounds were opened up and damaged muscle and fragments of $b$ me removed. The wounds wer irrigated with 1 in 1030 proflavine and thereafter completely stitche up excent for a drainage-tube, down to the bone, left in the anterio wound The drain was removed on the following day, and both wounds healed by first intention.

C. Wounds involving blood-vessels.-Four cases occurred where large blood-vessels were injured. The injuries involved the axillary, brachial, and radial arteries on the same arm, and the superficia femornl vein and a large branch of the femoral artery on the sam leg. In all cases the surrounding museles were much damaged. It i sufficient to record that, after dealing with the vessels, all the wound were completely sewn up after treatment with proflavine, and al healed without the least trouble.

\section{Results of Treatment with Protlavine.}

In the wounds treated by primary suture excellent results were obtained; in only one case out of 20 was it necessary to remove some of the stitches for drainage.

In some cases stitches were placed in situ at the time of operation and the wound left open with gauze packing for a day before the stitches were drawn tight. In all of these healing occurred as by first intention.

In wounds where primary closure was impossible owing to the amount of tissue removed the same set of changes occurred as were described for acriflavine. These changes were well seen in a case of amputation through the thigh and in some large wounds of soft parts. The surface of the wound became covered after a few days with a firm yellow pellicle and granulation tissue production was very slow. These wounds were then changed to other antiseptics, such as eusol. One case of gas gangrene occurred in the series, and a full account of this patient will be given.

An officer was admitted with a severe penetrating wound of the chest and severe shell wounds of the buttock. He was so much shocked on admission that nothing could be done for 12 hours. The butrock wounds were then drained and packed with gauze soaked in 1 in 1000 proflavine. The missile could not be found in any of the three buttoc wounds. The patient remained in very poor condition, chiefly owin to the severity of the chest wound, and after 24 hours an acute gas gangrene developed in the buttock. A fatal issue rapidly ensued.

Apart from this case no example of spreading sepsis was met with in the whole series of cases.

\section{Bacteriology of the Wounds.}

This can be dismissed very briefly, as the results are identical with those described for acriflavine. The same persistence of infection with coliform bacilli in the later stages of the wounds was again very noteworthy, and pyocyaneus infections were also common

\section{"In Vitro" Experiments with Proflavine.}

The same technique was adopted as that detailed in the report on acriflavine, and coliform bacilli isolated from wounds were used for the tests. In this instance parallel tests were set up with acriflavine and proflavine so as to compare the results.

In an experiment where the two salts were dissolved in normal saline growth of the coliform organisms used still occurred in a dilution of 1 in 50 of each substance. When dilutions were made in fresh human serum, the results of the test with the same organism were as follows :-
1 in 500
Proflavine.
1 in 1500
1 in 3000
1 in 5000
1 in 10,000
1 in 20,000 No growth.
Acriflavine.

These results seem to show that there is virtually no difference in the action of the two salts in test-tube experiments on the same test organism. 